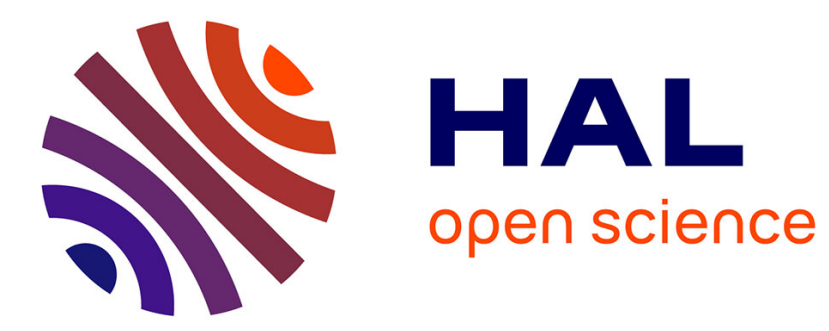

\title{
SECM Investigation of Carbon Composite Thermoplastic Electrodes
}

Kathleen E Berg, Yann R Leroux, Philippe Hapiot, Charles S Henry

\section{To cite this version:}

Kathleen E Berg, Yann R Leroux, Philippe Hapiot, Charles S Henry. SECM Investigation of Carbon Composite Thermoplastic Electrodes. Analytical Chemistry, 2021, 93 (3), pp.1304-1309. 10.1021/acs.analchem.0c01041 . hal-03102181

\section{HAL Id: hal-03102181 https://hal.science/hal-03102181}

Submitted on 31 Mar 2021

HAL is a multi-disciplinary open access archive for the deposit and dissemination of scientific research documents, whether they are published or not. The documents may come from teaching and research institutions in France or abroad, or from public or private research centers.
L'archive ouverte pluridisciplinaire HAL, est destinée au dépôt et à la diffusion de documents scientifiques de niveau recherche, publiés ou non, émanant des établissements d'enseignement et de recherche français ou étrangers, des laboratoires publics ou privés. 


\title{
SECM Investigation of Carbon Composite Thermoplastic Electrodes
}

\author{
Kathleen E. Berg ${ }^{1}$ Yann R. Leroux, ${ }^{2}$ Philippe Hapiot, ${ }^{2}$ Charles S. Henry ${ }^{1,3 *}$ \\ ${ }^{1}$ Department of Chemistry, Colorado State University, 1872 Campus Delivery, Fort Collins, CO, 80523, USA \\ ${ }^{2}$ Univ Rennes, CNRS, ISCR - UMR 6226, F-35000 Rennes, France \\ ${ }^{3}$ Department of Chemical \& Biological Engineering, Colorado State University, Fort Collins, CO, 80523, USA
}

\begin{abstract}
Thermoplastic electrodes (TPEs) are carbon composite electrodes consisting of graphite and thermoplastic polymer binder. TPE production is a solvent-based method, which makes them easy to fabricate and pattern into complex geometries, contrary to classical carbon composite electrodes. Depending on the composition (carbon type, binder, and composition ratio), TPEs can give excellent electrochemical performance and high conductivity. However, these TPEs are relatively new electrode materials, and thorough electrochemical characterization is still missing to understand and predict why large differences between TPEs exist. We used scanning electrochemical microscopy (SECM) as a screening tool to characterize TPEs. SECM data treatment based on scanning probe microscopy (SPM) imaging allows a fast and easy comparison of the numerous images, as well as the optimization of the preparation. Experiments suggest that TPEs behave as a network of interacting microelectrodes made by electrochemically active islands isolated between less active areas. Higher carbon content in TPEs is not always indicative of more uniform electrodes with better electrochemical performances. Using various SECM redox probes, it is possible to select a specific graphite or polymer type for the analyte of interest. For example, TPEs made with COC:3569 are the best compromise for general detection, whereas PMMA: $11 \mu \mathrm{m}$ is better suited for catechol-like polyphenols analysis.
\end{abstract}




\section{Introduction}

Carbon composite electrodes fabricated from graphite and a polymeric binder are a promising alternative to commercially available and homemade screen-printed electrodes. ${ }^{1-7}$ There has been a recent revitalization of using carbon composite thermoplastic electrodes (TPEs) using a simple, solvent-assisted fabrication method. ${ }^{8-10}$ TPEs are thermoplastic and carbon mixtures that are inexpensive and easy to prepare. They retain similar physical properties of the thermoplastic and the excellent electrochemical performance from the carbon additive. TPEs have been fabricated with a variety of carbon types (graphite and carbon black) and thermoplastics, including poly(methyl methacrylate) (PMMA), ${ }^{8}$ cyclic olefin copolymer $(\mathrm{COC})^{9}$ and poly-caprolactone (PCL). ${ }^{10}$ TPE electrochemical performance depends on the carbon, thermoplastic, and their corresponding ratio. Of the four carbon types initially tested, ${ }^{8}$ measured conductivities were up to 70 times higher than commonly available screen-printed carbon electrodes. Based on cyclic voltammetry investigations, electron transfer rates of common redox couples at TPEs were estimated to be significantly faster than at other commercial carbon materials electrodes. ${ }^{8}$ While some additional progress has been made in understanding the impact of carbon and polymer type, ${ }^{11,12}$ there has not yet been a thorough comparison of the different carbon and thermoplastic types that are required for the optimization of the TPEs properties. It is also unclear as to what gives rise to the thermoplastic and carbon mixture electrodes' high conductivity and improved electrochemical performances. Scanning electrochemical microscopy (SECM) in feedback mode appears as a convenient and adapted method for such optimization.

SECM is a well-known electrochemical technique complementary to cyclic voltammetry and other electrochemical methods, with the difference that SECM allows observation of electrochemical interfaces locally and from the solution side. ${ }^{13-16}$ It has been already used to probe a variety of biological, chemical and electrochemical processes. ${ }^{16-19}$ In feedback mode, ${ }^{19,20}$ the active form of an electro-active species (redox mediator) is generated at the tip ultramicroelectrode (UME) where it diffuses to the substrate surface, interacts with the substrate, and then diffuses back to the UME, creating a change in the electrochemical current. Feedback mode is of interest for our study because the sample under investigation does not need to be electrically connected (in unbiased conditions), and the method permits the observation of a specific property by changing the redox mediator. ${ }^{15,16,18,21}$ Quantitative kinetic analysis can be derived from approach curves that figure the variation of the UME tip current with the tip-substrate distance, or if the tip-substrate distance is held constant, twodimensional SECM images can be recorded. Hence, variation in current has to be analyzed depending on the topography and conductivity of the sample under investigation. The electrochemical activity that is seen by the SECM depends both on the charge transfer at the TPE surface and the ability of the sample to evacuate the charge thus providing a global relevant data for optimizing the TPE. Several theoretical and experimental papers have extensively addressed this issue these last two decades (for more detailed discussions about the conditions, general interest, limitations, see for example the references of Whitworth et $\mathrm{al}^{22}$ and Oleinick et $\mathrm{al}^{23}$ and references therein).

In this study, we principally used SECM to help define the best preparations for optimized electrode properties and as a first approach to understand the fundamental electrochemical TPE properties. Localized electrochemistry of TPEs was investigated as a function of thermoplastic, carbon type, and the ratio of thermoplastic to carbon. SECM images were recorded for a thorough comparison of the local electrochemical activity of TPEs. 24 different TPEs were investigated in this study, constituted of PMMA, COC, and PCL thermoplastics with four different carbon types (three different graphites and one carbon black) at two different thermoplastic to carbon ratios each. We chose ferrocenedimethanol $\left(\mathrm{Fc}(\mathrm{MeOH})_{2}\right)$, ferrocyanide $\left(\mathrm{Fe}(\mathrm{CN})_{6}{ }^{3-/ 4}\right)$, and dopamine as redox mediators in SECM experiments to yield more information about the electrochemical surface characteristics of each TPE. ${ }^{24}$ Fast criteria in the image analyses based on SPM methods are proposed in this work to rapidly evaluate the TPE quality from the SECM images.

\section{Materials and Methods}

All solutions were prepared with $18.2 \mathrm{M} \Omega \cdot \mathrm{cm}$ water (Milli-Q system, Billerica, MA, USA), and the chemicals were reagent grade from Sigma-Aldrich (MO, USA). TPE carbon types used were 7-11 $\mu \mathrm{m}$ graphite (“11 $\mu \mathrm{m}$ ”, 99\%, Alfa Aesar, MA, USA), 3569 graphite (“3569”, 99.9\% carbon, 96.9\% is $\leq 75 \mu \mathrm{m}$, Asbury Graphite Mills Inc, NJ, USA), MG1599 ("MG”, $15 \mu \mathrm{m}$, Great Lakes Graphite Inc., MA, USA), and acetylene carbon black (“Black”, 50 nm, STREM chemicals Inc., MA, USA). TPEs were fabricated as previously described. ${ }^{8-10}$ Briefly, PMMA (Optix, Plaskolite), COC (8007, TOPAS, MI, USA), and PCL (ThermoMorph) were dissolved in ethyl acetate, toluene, and dichloromethane, respectively. Carbon was added in specified ratios to the thermoplastic solution by mass (1:4 thermoplastic:carbon is equivalent to $80 \%$ carbon by mass) and thoroughly mixed. The solvent was evaporated (partially for PMMA and COC, fully for PCL), and the carbon composite material was heat pressed into $2.5 \mathrm{~mm}$-diameter holes in PMMA templates. The excess carbon composite material was removed by sanding. TPEs were freshly polished with P4000 (5 $\mu \mathrm{m}$ grit) sandpaper before measurements. For the PCL TPEs studied over time, the PCL electrodes were stored in air between measurements after fabrication and then freshly polished with P4000 sandpaper immediately before measurements.

AFM measurements were performed with an NT-MDT Ntegra microscope in tapping mode using ACTA tips (AppNano Inc, CA, USA) on freshly polished TPEs. All images were $10 \times 10 \mu \mathrm{m}^{2}$ with $400 \times 400$ data points. Data analysis was

\section{ACCEPTED MANUSCRIPT}


performed with Gwyddion software. ${ }^{25}$ SECM measurements were performed using a homemade setup to that previously described ${ }^{26}$ with an Autolab PGSTAT 12 (Methohm, Utrecht, Netherlands) potentiostat. The SECM setup is equipped with an adjustable stage for the tilt angle correction and controlled by the SECMx software written by Wittstock, G., et al. ${ }^{27}$ All redox probes were selected based on previous SECM studies that have demonstrated their possibilities for SECM experiments. ${ }^{26}$ SECM measurements were performed using a 3-electrode configuration in feedback mode, with a $10 \mu \mathrm{m}$ diameter Pt electrode ( $\mathrm{CH}$ Instruments Inc, TX, USA) as the tip working electrode, $\mathrm{Ag} / \mathrm{AgCl}$ (saturated $\mathrm{KCl}$ ) reference electrode, and a Pt wire as a counter electrode. Fitting of the experimental approach curves with the corresponding theoretical behavior were obtained following Lefrou's approximations. ${ }^{28}$ The RG value of the working electrode $(\mathrm{RG}=$ 5.6) was calculated from negative approach curves on glass. The applied potential at the tip electrode was set at the diffusion plateau of the mediator to allow fast electron transfer at the tip electrode. TPEs were not electrically connected (unbiased conditions). Tilt angle correction was performed using an adjustable stage, and the tilt was corrected on each TPE sample using negative feedback curves on the thermoplastic template near the electrode. $100 \times 100 \mu \mathrm{m}^{2}$ images were taken at a normalized distance of 1 , determined by touching the surface and moving the UME back from the surface $5 \mu$ m, and values are reported as normalized current $\left(\mathrm{i} / \mathrm{i}_{\text {inf }}\right.$ ). The normalized distance is determined as $\mathrm{L}=\mathrm{d} / \mathrm{a}$ where $\mathrm{d}$ is the distance from the substrate and the radius of the UME. The SECM images shown are data taken from left to right in each image. Fresh solutions of $1 \mathrm{mM} \mathrm{Fc}(\mathrm{MeOH})_{2}$ in $0.1 \mathrm{M} \mathrm{H}_{2} \mathrm{SO}_{4}$ and $\left.1 \mathrm{mM} \mathrm{K} \mathrm{Fe}_{(\mathrm{CN}}\right)_{6}$ in $0.5 \mathrm{M} \mathrm{KCl}$ images were taken as 50 x $2 \mu \mathrm{m}$, and $1 \mathrm{mM}$ L-dopamine in $0.1 \mathrm{M} \mathrm{H}_{2} \mathrm{SO}_{4}$ were taken as 25 x $4 \mu \mathrm{m}$. Images were acquired at room temperature. SECM image data analysis was performed with Gwyddion software. ${ }^{25}$

\section{Results and Discussion}

Because TPE sensitivity is related to its electrochemical activity, and SECM evaluates the current density passing through the substrate at a local scale allowing its optimization for the highest and the most homogeneous signal, 24 different TPEs were analyzed and screened by SECM in this study. The TPEs were fabricated with four different carbon types (three graphites: “11 $\mu \mathrm{m}$ ”, “3569”, “MG” and one carbon black, "Black”) and three different thermoplastics (PMMA, COC, and PCL) at two different thermoplastic to carbon ratios each. These different carbon types were chosen because they present relatively high conductivity and low capacitance. ${ }^{10}$ The thermoplastics were tested for variances in surface roughness and electrochemical heterogeneity. The ratios of thermoplastic to carbon are chosen to be the lowest and highest carbon mass content possible between the three thermoplastics. For example, carbon black TPEs cannot be fabricated with higher than a 1:1 thermoplastic:carbon black ratio because the material breaks apart after solvent evaporation, which leads to an undefined and unpolishable electrode surface that is also unable to be physically manipulated; the conductivity is too low below a 3:1 thermoplastic:carbon black ratio to be a practical electrode. Therefore, we measured the 3:1 and 1:1 thermoplastic:carbon black ratios, 1:1 and 1:5 thermoplastic:carbon ratios with both the $11 \mu \mathrm{m}$ and 3569 graphites, and 1:1 and 1:4 thermoplastic:MG ratios. Both images and approach curves were recorded. SECM images show variations of the normalized current $\left(\mathrm{i} / \mathrm{i}_{\text {inf }}\right)$ in the xy plane at a fixed distance from the TPE surface, whereas approach curves show variations of the normalized current as a function of the normalized distance $(\mathrm{L}=$ d/a) from the TPE surface at one position on the electrode surface. As an example, SECM investigation of 1:1 PMMA:MG TPE is shown in Figure 1, using 1,1'-ferrocenedimethanol $\left(\mathrm{Fc}(\mathrm{MeOH})_{2}\right)$ as the mediator. The observed heterogeneous electrochemical activity agrees well with the previously published SEM images of TPEs, where there are more active electron transfer regions across the surfaces. ${ }^{8-9}$ 

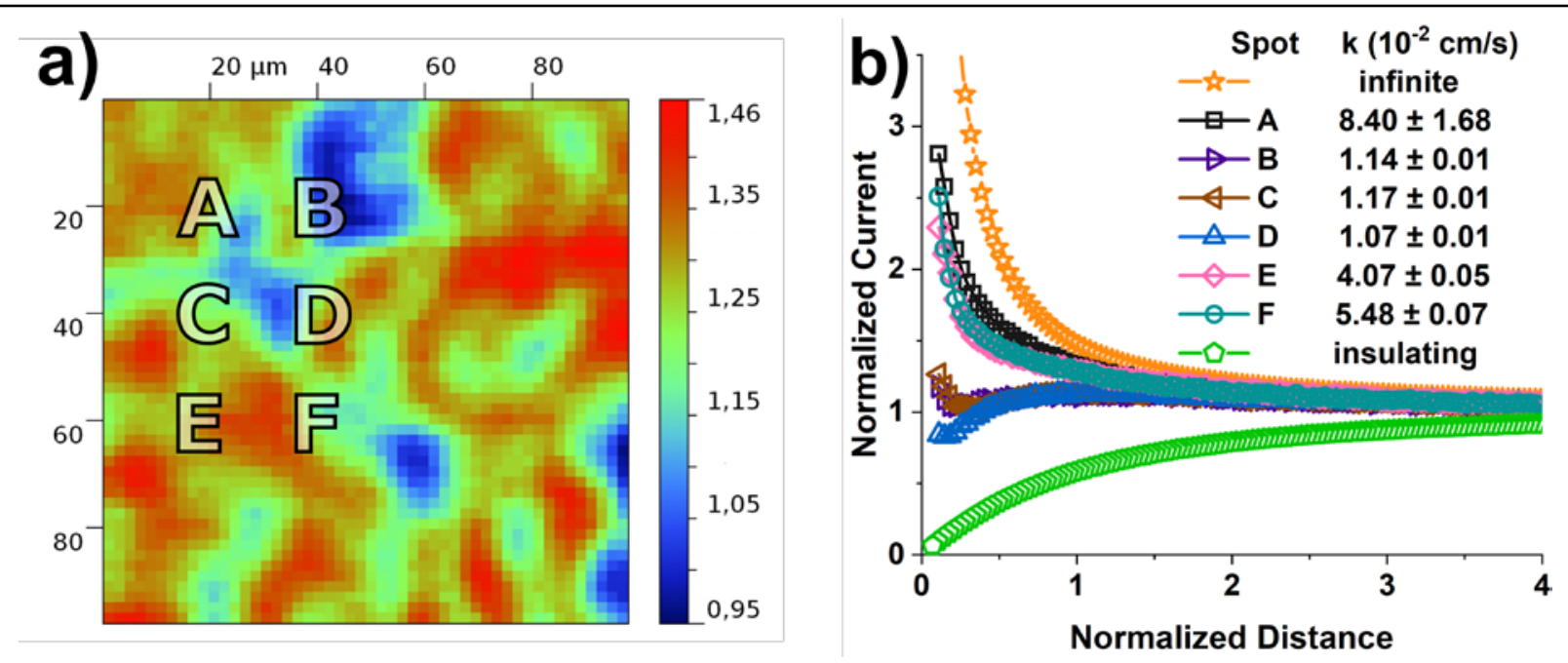

Figure 1: 1:1 PMMA:MG TPE (a) $100 \times 100 \mu \mathrm{m}^{2}$ SECM image (rainbow-colored scale bar is the image's normalized current values) and (b) approach curves taken with $\mathrm{Fc}(\mathrm{MeOH})_{2}$ at points $\mathrm{A}, \mathrm{B}, \mathrm{C}, \mathrm{D}, \mathrm{E}$, and F corresponding to the image with apparent rate constant $\left(\mathrm{k}, 10^{-2} \mathrm{~cm} \mathrm{~s}^{-1}\right)$ values calculated from fitted approach curves. Both were taken with a $10 \mu \mathrm{m}$ diameter Pt UME. Image mean value is 1.27 . The image start point is at 0,0 ( $\mu \mathrm{m}$, upper left corner) and ends at 100,100 ( $\mu \mathrm{m}$, lower right corner) and was scanned left to right.

Six approach curves were also taken at the points indicated on the SECM image shown in Figure 1a, using the same mediator. Approach curves at points A, E, and F show positive feedback character; whereas points B, C, and D record an intermediate feedback character. The feedback character is in accordance with the obtained surface electrochemical mapping obtained in Figure 1a, where points B, C, and D were taken between insulating and conducting regions. Negative (insulating k) and positive feedback (infinite k) curves are also shown in Figure 1 for reference. One could observe an intermediate feedback character, and for some curves ( $D$ and $C$ ), a decrease then re-increase of the tip-current at short distances. This behavior is expected for surfaces presenting reactive areas slightly smaller than the tip electrode size. ${ }^{29}$ This is similar to the "partially blocked electrode" behavior (see for example the works of C. Amatore ${ }^{30}$ or R.G. Compton $^{31}$ ) where the derived apparent charge transfer rate constant characterizes the performance of the electrode. The resulting apparent rate constant, $\mathrm{k}$, values considering a simple electron transfer (Lefrou's approximation) are listed in Figure $1 .{ }^{32}$ In the more active areas, positive feedback with apparent k values are obtained in the range of $4-810^{-2} \mathrm{~cm} \mathrm{~s}^{-1}$, indicating a relatively fast electron exchange between the surface and the molecule in solution.

The SECM images yield a better global view of the electrode surface's electrochemical activity relative to a few approach curves, notably for evaluating the heterogeneity. For the complete surface investigation of TPEs' electrochemical activity, $100 \times 100 \mathrm{~mm}^{2}$ SECM images were recorded and assumed to be more representative of the electrode surface than an approach curve for each surface. We used three different mediators with fast electron transfer kinetics, which is required in unbiased conditions: ${ }^{19}$ ferrocenedimethanol $\left(\mathrm{Fc}(\mathrm{MeOH})_{2}\right)$, ferrocyanide $\left(\mathrm{Fe}(\mathrm{CN})_{6}{ }^{3-/ 4}\right)$, and dopamine. These mediators were chosen because different information can be obtained from each to discriminate between activity, charge transport inside the TPE and topography (see for example Leroux et al ${ }^{33}$ and Blanchard et al. ${ }^{34}$ ). Ferrocene derivatives are not known to be surface sensitive due to their outer sphere character. On the contrary, Fe(CN) $6^{3-/ 4-}$ and dopamine are surface sensitive. More specifically, dopamine is known to be surface sensitive to oxides with adsorption required. ${ }^{26,35}$ SECM analyses of the 24 different TPEs using three different mediators generated a total of 72 images. For a rapid evaluation of such large data set, images were treated in a similarly way to other scanning probe microscopy with Gwyddion software. ${ }^{19}$ For each image, we determined the average normalized current value (i/i inf), the maximum and minimum current values, and the normalized current RMS (can also be viewed as electrochemical heterogeneity here). A good electrode with high activity should present the highest average normalized current and the lowest normalized current RMS for the three mediators. For example, the SECM image of Figure 1 (1:1 PMMA:MG) shows heterogeneous electrochemical activity with an average normalized current value (i/inf) of 1.27 and a normalized current RMS of 0.091 . It is important to note that variations in electrochemical activity are not due to surface topography because the surface roughness measured by AFM was $4 \mathrm{~nm}$ for the 1:1 PMMA:MG TPE (Supporting Information), and the electrode diameter is much larger (10 $\mu \mathrm{m}$ in diameter), which leads to minimal effects caused by the TPE surface topography. The lack of surface topography effect is further supported by observing differences in electrochemical current that are dependent upon 
the redox probe that was used to image the TPEs (for comparison, see Supporting Information SECM images of 1:1 PMMA:MG). To help evaluate the reproducibility of the images, we imaged two electrode types (1:1 PMMA:11 $\mu \mathrm{m}$ and 1:4 PMMA:MG) three different times, each in different locations. The 1:1 PMMA:11 $\mu$ images (average normalized current \pm current RMS, minimum current-maximum current) were 1.76 \pm 0.015, 1.71-1.80; 1.80 \pm 0.048, 1.40-2.10; and $1.80 \pm 0.029,0.31-2.10$. The 1:4 PMMA:MG images (average normalized current \pm current RMS, minimum currentmaximum current) were $1.30 \pm 0.027,1.20-1.44 ; 1.36 \pm 0.016,1.23-1.39$; and $1.15 \pm 0.004,1.14-1.16$. While imaging a portion of the electrode inherently cannot include data for the entire electrode surface, it can give estimates faster while maintaining consistent experimental set up (e.g. minimizing concentration differences due to evaporation over time).

A graphical summary of the SECM experiments obtained for PMMA and COC TPEs is shown in Figure 2. Original SECM images with the table of corresponding numerical data can be found in Supporting Information. As previously discussed, due to its outer-sphere character, $\mathrm{Fc}(\mathrm{MeOH})_{2}$ can transfer charges by direct and indirect processes. On the contrary, inner-sphere redox probes as dopamine and ferrocyanide exchange charges with the surface by direct transfer because they need a direct interaction with the carbon substrate for an efficient rate. As seen in Figure 2, SECM images measured with $\mathrm{Fc}(\mathrm{MeOH})_{2}$ exhibit higher average normalized current density than the ones measured with dopamine and ferrocyanide. It agrees with a higher electron transfer rate as generally observed for ferrocene derivatives. Considering the images performed with $\mathrm{Fc}(\mathrm{MeOH})_{2}$, one could observe that increasing the carbon content doesn't systematically lead to higher electrochemical responses. For example, TPEs prepared with PMMA as a polymeric binder show the highest average normalized current densities for both $11 \mu \mathrm{m}$ and 3569 carbon materials at the lowest carbon ratio. Using MG or carbon black as a carbon source leads to similar normalized currents for both carbon ratios. Carbon particle size does not play a considerable role here as MG and $11 \mu \mathrm{m}$ carbon have similar particle size. On the contrary, with COC as polymeric binder, a higher carbon content leads to a higher electrochemical activity as expected. Here again, carbon particle size does not play a major role for the electrochemical activity, even if the highest activity is obtained with the smallest carbon particles (carbon black). Analyses of SECM images recorded with the inner-sphere redox probes (i.e. dopamine and ferrocyanide) provide a different view. With dopamine, for both PMMA and COC polymeric binders, a higher carbon content leads to a higher electrochemical activity with PMMA:11 $\mu \mathrm{m}$ being the most reactive TPEs. Using ferrocyanide, a higher carbon content also leads to a higher electrochemical activity when using COC as polymeric binder. However, as observed for $\mathrm{Fc}(\mathrm{MeOH})_{2}$, when using PMMA, a higher carbon content doesn't always lead to a higher electrochemical response and the type of carbon giving higher electrochemical activity at the lowest carbon content is not the same as with $\mathrm{Fc}(\mathrm{MeOH})_{2}$. Here, $11 \mu \mathrm{m}$ and MG lead to higher average normalized current density at the lowest carbon content whereas 3569 and carbon black have the opposite effect.

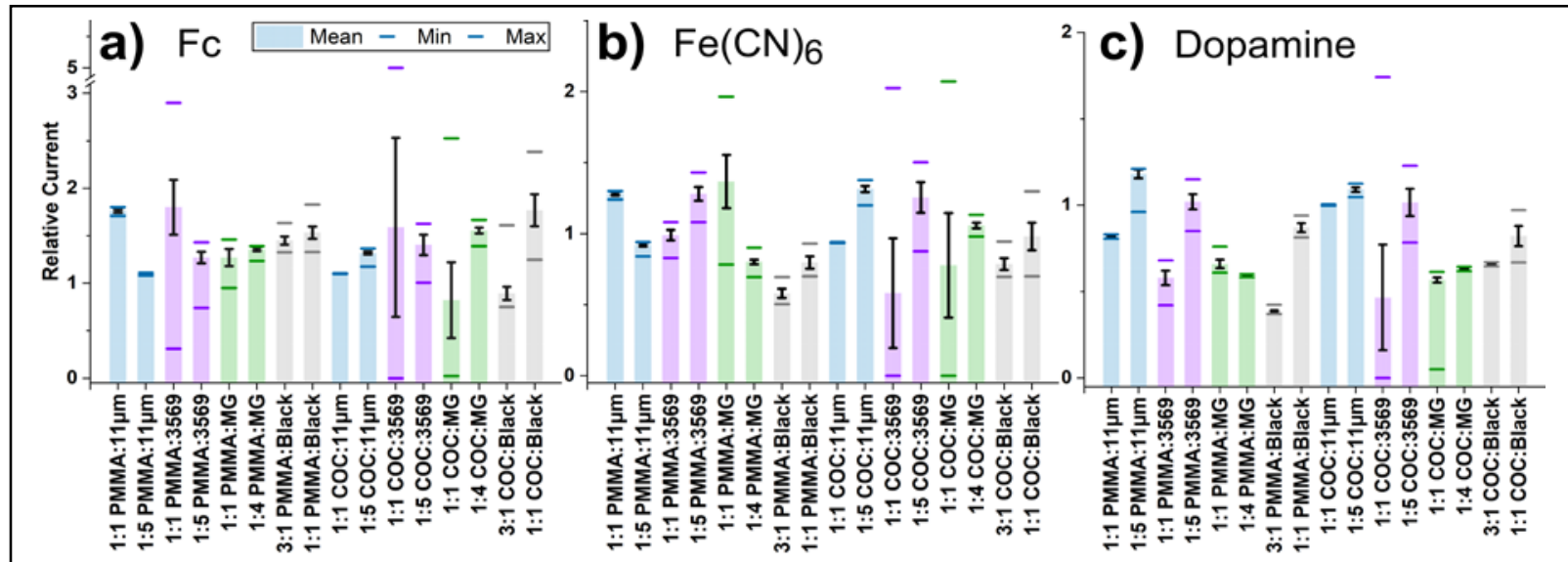

Figure 2: SECM image summary results of PMMA and COC TPEs using (a) Fc(MeOH) 2 in $100 \mathrm{mM} \mathrm{H}_{2} \mathrm{SO}_{4}$, (b) $\mathrm{Fe}(\mathrm{CN})_{6}^{3-/ 4-}$ in $500 \mathrm{mM} \mathrm{KCl}$, and (c) dopamine in $100 \mathrm{mM} \mathrm{H}_{2} \mathrm{SO}_{4}$. The column bars represent the mean value, black error bars represent mean \pm 1 RMS (electrochemical current), and the upper and lower bars represent the maximum and minimum current, respectively. Relative current values are the measured current normalized by the infinite current. For a better viewing, y-scale are different for the mediators.

Differences are observed between redox mediators used here in SECM imaging. Dopamine has been reported to require surface adsorption for fast electron transfer. ${ }^{23,24}$ Dopamine electron transfer is also strongly dependent on surface oxide functional groups or surface hydrogen bonding electrocatalytic sites. McCreery et al. reported that dopamine has higher electrochemical response at edge plane than at basal plane graphite. ${ }^{24,36}$ While dopamine electrocatalytic sites may result from polishing, ${ }^{8,25}$ all TPEs were similarly polished immediately before imaging. Electrochemical activity of $\mathrm{Fe}(\mathrm{MeOH})_{2}$ is less dependent of surface states due to its outer-sphere character but $\mathrm{Fe}(\mathrm{CN})_{6}{ }^{3-4-}$ could also have a variable response 
with its surface interactions. ${ }^{26}$ It is difficult to totally rationalize the observed variations between redox probes. We observed that the size of the carbon particle has a limited influence on the electrochemical activity that is more dependent on surface functional groups. Unfortunately, little information on surface functional groups are provided by carbon manufacturers. For future studies evaluating analytes, the choice of carbon type allows an increase or decrease of the electrode electrochemical response depending on the nature of the molecule under investigation. The electrochemical activity differences seen between COC and PMMA TPEs (when comparing the same carbon type) are probably related to how the polymers coat the carbon particles. The use of either will likely depend on the analyte of interest and solution conditions (solvent, fabrication requirements, etc.). For example, COC was employed over PMMA when creating electrochemical biosensors because of COC's high purity, chemical resistance, and biocompatibility. ${ }^{9}$

PCL provides an alternative, simpler fabrication process for TPEs than PMMA and COC. PCL TPEs were also recently incorporated into microfluidic devices. ${ }^{8,11}$ However, the signals from PCL TPEs change over time (PMMA and COC TPEs have not shown bulk signal changes over several months). ${ }^{9,10}$ PCL is also a well-known biodegradable polymer, but its degradation time is not well controlled and takes up to two years in physiological conditions. ${ }^{37-39}$ Here, we used $\mathrm{Fc}(\mathrm{MeOH})_{2}$ as redox mediator in SECM experiments to probe the electrochemical response of PCL TPEs at three different times: fresh, two days and two weeks after fabrication. All TPEs were freshly polished before each measurement. As seen in Figure 3, variations in electrochemical activity are seen with increased time. First, it is interesting to note that freshly prepared PCL TPEs fabricated with the three different graphites (3569 graphite, MG graphite and $11 \mu \mathrm{m}$ graphite) present higher electrochemical response to $\mathrm{Fc}(\mathrm{MeOH})_{2}$ than their analogue fabricated with PMMA and COC. Secondly, the PCL TPEs do show a decrease in electrochemical activity over time, as measured by SECM. The largest diminution of electrochemical activities was observed for PCL-based TPEs at low thermoplastic to carbon ratio. The largest diminution observed is a loss of $60 \%$ of electrochemical activity after two weeks for 1:5 PCL:11 $\mathrm{mm}$ and 1:5 PCL:3569. PCL TPEs made with MG graphite show a smaller maximum diminution of electrochemical activity of 30\% after two weeks. Finally, PCL-based TPEs fabricated with carbon black did not show decrease in electrochemical activities over time. The electrochemical activity of the lower carbon ratio TPE (3:1 PCL:Black) stayed about the same throughout all experiments, whereas the higher carbon ratio TPE (1:1 PCL:Black) normalized current values approximately doubled (0.62 to 1.20$)$ from the freshly fabricated electrode to the two day old electrode and then decreased to 0.93 when measured two weeks after fabrication. Overall, if PCL TPEs are used for analytical purposes, a more thorough electrode characterization to test their long-term stability and reproducibility is needed.

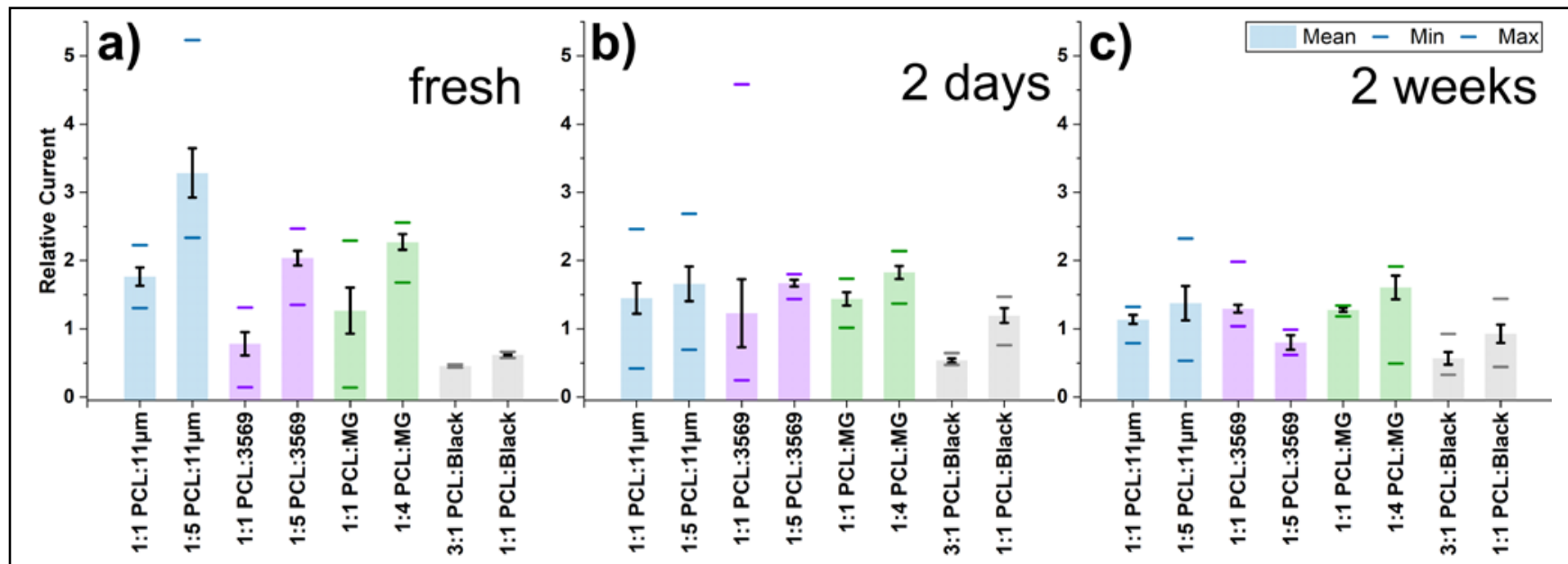

Figure 3: SECM image summary of PCL TPEs at three different times: freshly made (a, "fresh”), two days old (b, “2 days”), and 2 weeks old (c, " 2 weeks"). The column bars represent the mean value, black error bars represent mean \pm 1 RMS (electrochemical), and the upper and lower bars represent the maximum and minimum current, respectively. Relative current values are measured current normalized by the infinite current using $1 \mathrm{mM} \mathrm{Fc}(\mathrm{MeOH})_{2}$ in $100 \mathrm{mM} \mathrm{H}_{2} \mathrm{SO}_{4}$. TPEs were freshly polished before obtaining images.

\section{Conclusions}

SECM was successfully used to rapidly screen the local electrochemical activities of various thermoplastic electrodes (TPEs). Data from 72 SECM images were collected, and average normalized currents with current RMS values were extracted, allowing us to easily compare each TPE relatively quickly. First, we were able to show that TPEs show regions with high and low active electron transfer suggesting that they behave as a network of interacting microelectrodes or in other words that they are constituted of actives areas of different electrochemical activity. Second, SECM experiments show that increasing carbon content in TPEs does not necessarily yields more electroactive electrodes. SECM studies 
reveal differences between TPEs made with PMMA or COC as thermoplastic depending on the analyte under investigations. Among the considered electrodes, TPEs made with COC:3569 in a 1:5 thermoplastic to carbon ration appears as the best compromise when considering an electrode for sensing outer-sphere and inner-sphere analytes. For future studies evaluating analytes with electrochemical behavior similar to dopamine, polyphenols, TPEs fabricated with PMMA:11 $\mu \mathrm{m}$ in a 1:5 ratio display the highest response. While differences are observed between PMMA and COC based TPEs, the use of either will be mainly dependent on their environment (solvents, analytes, and fabrication requirements). Finally, we observed substantial changes over time in electrochemical responses of TPEs made with PCL. TPEs made with carbon black and PCL appear to be relatively stable compare to other carbon sources, even if future studies investigating and addressing the stability of PCL-based TPEs need to be performed before analytical usage.

\section{ASSOCIATED CONTENT}

\section{Supporting Information}

Supporting information section shows the values for Figure 2, raw SECM images with the different mediators, and AFM analyses.

The Supporting Information is available free of charge on the ACS Publications website.

\section{AUTHOR INFORMATION}

\section{Corresponding Author}

* chuck.henry@colostate.edu

\section{Author Contributions}

The manuscript was written through contributions of all authors.

\section{ACKNOWLEDGMENT}

We thank Dr. Yara Aceta for her SECM training. This material is based upon research supported by the Chateaubriand Fellowship of the Office for Science \& Technology of the Embassy of France in the United States. This material is also supported by the National Science Foundation under Grant No. CHE-1710222.

\section{REFERENCES}

1. Falat, L.; Cheng, H. Y., Voltammetric Differentiation of Ascorbic-Acid and Dopamine at an Electrochemically Treated Graphite Epoxy Electrode. Analytical chemistry 1982, 54, 2108-2111.

2. Henriques, H. P.; Fogg, A. G., Preparation of Graphite-Loaded Epoxy-Based Voltammetric Electrodes Using a Multi-Layer Coating and Hardening Technique. Analyst 1984, 109, 1195-1199.

3. Perween, M.; Parmar, D. B.; Bhadu, G. R.; Srivastava, D. N., Polymer-graphite composite: a versatile use and throw plastic chip electrode. Analyst 2014, 139, 5919-26.

4. Zhong, S.; Kazacos, M.; Burford, R. P.; Skyllas-Kazacos, M., Fabrication and Activation Studies of Conducting Plastic Composite Electrodes for Redox Cells. J Power Sources 1991, 36, 29-43.

5. Mclaren, K. G.; Batley, G. E., Radiation-Cured Polymer-Impregnated Graphite Electrodes for Anodic-Stripping Voltammetry. J Electroanaly Chem 1977, 79, 169-178.

6. Tallman, D. E.; Petersen, S. L., Composite Electrodes for Electroanalysis - Principles and Applications. Electroanalysis 1990, 2, 499-510.

7. Yao, X.; Wu, H.; Wang, J.; Qu, S.; Chen, G., Carbon nanotube/poly(methyl methacrylate) (CNT/PMMA) composite electrode fabricated by in situ polymerization for microchip capillary electrophoresis. Chemistry 2007, 13, 846-53.

8. Klunder, K. J.; Clark, K. M.; McCord, C.; Berg, K. E.; Minteer, S. D.; Henry, C. S., Polycaprolactone-enabled sealing and carbon composite electrode integration into electrochemical microfluidics. Lab Chip 2019, 19, 2589-2597. 
9. $\quad$ Noviana, E.; Klunder, K. J.; Channon, R. B.; Henry, C. S., Thermoplastic Electrode Arrays in Electrochemical Paper-Based Analytical Devices. Anal Chem 2019, 91, 2431-2438.

10. Klunder, K. J.; Nilsson, Z.; Sambur, J. B.; Henry, C. S., Patternable Solvent-Processed Thermoplastic Graphite Electrodes. J Am Chem Soc 2017, 139, 12623-12631.

11. Pradela-Filho, L. A.; Noviana, E.; Araujo, D. A. G.; Takeuchi, R. M.; Santos, A. L.; Henry, C. S., Rapid Analysis in Continuous-Flow Electrochemical Paper-Based Analytical Devices. ACS Sens 2020, 5, 274-281.

12. Berg, K. E.; Leroux, Y. R.; Hapiot, P.; Henry, C. S., Increasing Applications of Graphite Thermoplastic Electrodes with Aryl Diazonium Grafting. Chemelectrochem 2019, 6, 4811-4816.

13. Polcari, D.; Dauphin-Ducharme, P.; Mauzeroll, J., Scanning Electrochemical Microscopy: A Comprehensive Review of Experimental Parameters from 1989 to 2015. Chem Rev 2016, 116, 1323413278.

14. Bard, A.; Mirkin, M., Scanning Electrochemical Microscopy, CRC Press. Taylor and Francis, Boca Raton, FL: 2012.

15. Amemiya, S.; Bard, A. J.; Fan, F. R.; Mirkin, M. V.; Unwin, P. R., Scanning electrochemical microscopy. Annu Rev Anal Chem, 2008, 1, 95-131.

16. Wittstock, G.; Burchardt, M.; Pust, S. E.; Shen, Y.; Zhao, C., Scanning electrochemical microscopy for direct imaging of reaction rates. Angew Chem Int Ed Engl 2007, 46, 1584-617.

17. Bard, A.; Mirkin, M., Scanning Electrochemical Microscopy Marcel Dekker. New York 2001.

18. Pust, S. E.; Maier, W.; Wittstock, G., Investigation of Localized Catalytic and Electrocatalytic Processes and Corrosion Reactions with Scanning Electrochemical Microscopy (SECM). Z Phys Chem 2008, 222, 1463-1517.

19. Bard, A. J.; Fan, F. R.; Pierce, D. T.; Unwin, P. R.; Wipf, D. O.; Zhou, F., Chemical imaging of surfaces with the scanning electrochemical microscope. Science 1991, 254, 68-74.

20. Lagrost, C.; Leroux, Y.; Hapiot, P., Localized Electrochemistry for Studying Functional Carbon Surfaces. Electroanalysis 2016, 28, 2680-2687.

21. Bard, A. J.; Mirkin, M. V., Scanning electrochemical microscopy. CRC Press: 2012.

22. Whitworth, A. L.; Mandler, D.; Unwin, P. R., Theory of scanning electrochemical microscopy (SECM) as a probe of surface conductivity. PCCP 2005, 7, 356-365.

23. Oleinick, A. I.; Battistel, D.; Daniele, S.; Svir, I.; Amatore, C., Simple and clear evidence for positive feedback limitation by bipolar behavior during scanning electrochemical microscopy of unbiased conductors. Anal Chem 2011, 83, 4887-93.

24. McCreery, R. L., Advanced carbon electrode materials for molecular electrochemistry. Chem Rev 2008, 108, 2646-87.

25. Nečas, D.; Klapetek, P., Gwyddion: an open-source software for SPM data analysis. Open Phys 2012, 10, 181-188.

26. Lhenry, S.; Leroux, Y. R.; Hapiot, P., Use of catechol as selective redox mediator in scanning electrochemical microscopy investigations. Anal Chem 2012, 84 (17), 7518-24.

27. Sklyan, O.; Wittstock, G.; Numes Kirchner, C.; Leash, A., SECMX software.

28. Lefrou, C.; Cornut, R., Analytical expressions for quantitative scanning electrochemical microscopy (SECM). Chemphyschem 2010, 11, 547-56.

29. Bard, A. J.; Mirkin, M. V.; Unwin, P. R.; Wipf, D. O., Scanning Electrochemical Microscopy .12. Theory and Experiment of the Feedback Mode with Finite Heterogeneous Electron-Transfer Kinetics and Arbitrary Substrate Size. J Phys Chem 1992, 96, 1861-1868.

30. Amatore, C.; Savéant, J. M.; Tessier, D., Charge transfer at partially blocked surfaces: A model for the case of microscopic active and inactive sites. J Electroanaly Chem Inter Electrochem 1983, 147, 39-51.

31. Menshykau, D.; Compton, R. G., Electrodes modified with electroinactive layers: distinguishing through-film transport from pinhole (pore) diffusion. Langmuir 2009, 25, 2519-29. 
32. Cornut, R.; Lefrou, C., New analytical approximation of feedback approach curves with a microdisk SECM tip and irreversible kinetic reaction at the substrate. $J$ Electroanaly Chem 2008, 621, 178-184.

33. Leroux, Y. R.; Hapiot, P., Nanostructured monolayers on carbon substrates prepared by electrografting of protected aryldiazonium salts. Chem Mater 2013, 25, 489-495.

34. Blanchard, P. Y.; Sun, T.; Yu, Y.; Wei, Z.; Matsui, H.; Mirkin, M. V., Scanning Electrochemical Microscopy Study of Permeability of a Thiolated Aryl Multilayer and Imaging of Single Nanocubes Anchored to It. Langmuir 2016, 32, 2500-8.

35. DuVall, S. H.; McCreery, R. L., Self-catalysis by catechols and quinones during heterogeneous electron transfer at carbon electrodes. JACS 2000, 122, 6759-6764.

36. McCreery, R. L.; McDermott, M. T., Comment on Electrochemical Kinetics at Ordered Graphite Electrodes. Analy Chem 2012, 84, 2602-2605.

37. Perveen, R.; Nasar, A., Multiwalled carbon nanotube-based nanocomposites for artificial bone grafting. In Applications of Nanocomposite Materials in Orthopedics, Elsevier: 2019; pp 111-126.

38. Prabhakar, R. L.; Brocchini, S.; Knowles, J. C., Effect of glass composition on the degradation properties and ion release characteristics of phosphate glass--polycaprolactone composites. Biomaterials 2005, 26, 2209-18.

39. Saad, B.; Suter, U., Biodegradable polymeric materials. 2001. 
For Table of Contents Only

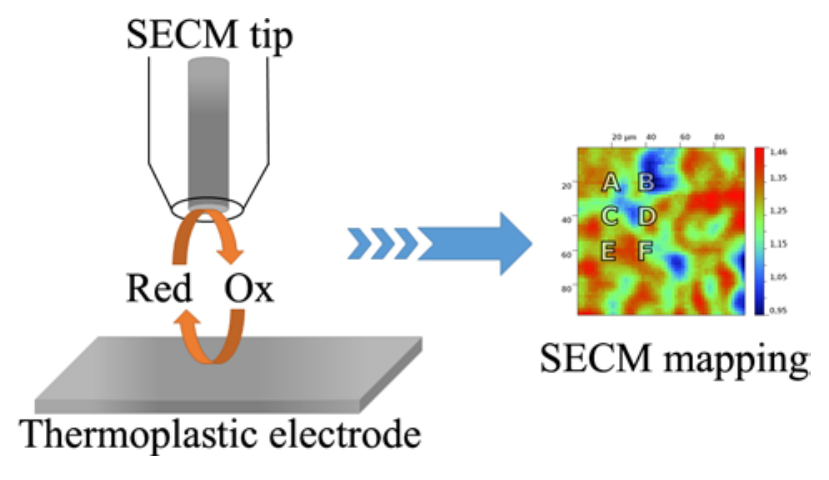

